\title{
El retorno a la política \\ Incertidumbre, deliberación y acción política en la teo- ría de la democracia de Benjamin R. Barber
}

\author{
ANTONIO CHAPA LLUNA \\ Universidad de Valencia (España) \\ antoniochapalluna@gmail.com
}

\begin{abstract}
Resumen
La teoría de Benjamin Barber ha renovado por varias razones su actualidad al cumplirse 30 años de la edición de Strong Democracy. Me interesa desarrollar en este artículo la relación que Barber establece entre la necesidad de la acción política, la incertidumbre epistemológica del ámbito político y la deliberación. Reconocer esta relación puede ayudarnos a explicar la inevitabilidad de la política y, por tanto, retornar a ella. No cabe duda de que en nuestros tiempos globalizados es fácil reconocer la necesidad de la acción y la incertidumbre, por lo que la teoría de Barber puede indicarnos cómo sobrellevarlas. Si la propuesta de Barber fue en su momento una inspiración para nuestras pretensiones de renovación democrática, la situación actual de nuestras democracias requiere que recuperemos ese espíritu de renovación.
\end{abstract}

Palabras clave: Democracia deliberativa, democracia epistémica, deliberación, participación, ciudadanía, conflicto político.

\section{Return to politics \\ Uncertainty, debate and political action in the theory of democra- y Benjamin R. Barber}

\begin{abstract}
The theory of Benjamin Barber has renewed its topicality after the thirtieth anniversary of the publication of Strong Democracy. My aim in this paper is to explain the relationship established by Barber between the necessity of political action, epistemological uncertainty and deliberation. Acknowledging this relationship can belp us explain the inevitability of politics and the necessity of return to it. There is no doubt that in our globalized world it is easy to recognize the necessity of political action and uncertainty; Barber's theory can help us cope with them. If his proposal was in its time an inspiration for our desires of democratic renovation, the current situation of our democracies requires us to recover that spirit of renovation.
\end{abstract}

Key words: Deliberative democracy, epistemic democracy, deliberation, participation, citizenship, political conflict.

Doctor en Filosofía, Universidad de Valencia (España). 
La crisis económica de 2008 ha revelado erga omnes lo que Adela Cortina ya afirmaba a principios de la década de 1990: la Historia no ha acabado (Cortina, 1991: 19-25) ${ }^{1}$. La gestión de las cosas no ha sustituido a la política, la democracia liberal y la economía de mercado ya no aseguran ni para las clases medias del primer mundo la apariencia de la anhelada Shangri-la. La Política, con mayúsculas, nunca se fue, tal vez algunos pretendieron huir de ella, pero tendrán que retornar.

En este contexto, creo pertinente recuperar la teoría política de Benjamin R. Barber que destaca entre quienes nunca abjuraron del reconocimiento de la centralidad de la política. Su propuesta está presidida por el concepto de Strong Democracy, definida como «un modelo participativo de política, donde el conflicto se resuelve en ausencia de un presupuesto independiente, a través de un proceso de autogobierno participativo y cercano y de la creación de una ciudadanía capaz de transformar a individuos privados y dependientes en ciudadanos libres e intereses privados y parciales en bienes públicos» (Barber, 1984: 132).

La teoría de Barber ha renovado por varias razones su actualidad al cumplirse 30 años de la edición de Strong Democracy. En primer lugar, desde sus primeros escritos Barber recupera el radicalismo democrático del pragmatismo de Dewey $^{2}$, una especie de profetismo ${ }^{3}$ que reivindica la dimensión emancipadora de una democracia que no puede guardar connivencia con situaciones de injusticia o dominación.

En segundo lugar, Barber pretende sintetizar los rasgos irrenunciables del liberalismo con otros del republicanismo que pueden revitalizar nuestras democracias. La relación entre elementos liberales y republicanos dota de complejidad a la teoría de Barber, pero esa complejidad, como afirma Herrera (2005), es parte de la tradición política occidental. Sin tener en cuenta esta complejidad no es posible comprender el debate acerca de la democracia contemporánea, como bien muestra Gil Soldevilla (2004) al destacar los rasgos comunes de las versiones liberales, republicanas y de raigambre comunitaria.

\footnotetext{
1 Cortina (1993b) critica el neopragmatismo de Richard Rorty y discrepa de algunos rasgos del neopragmatismo de Benjamin Barber, pero su negación del fin de la Historia confluye con la pretensión de Barber de que la democracia se mantenga como horizonte normativo capaz de criticar nuestras democracias reales.

2 El radicalismo democrático de Dewey es analizado por Del Castillo (1996), quien señala la ruptura que produce en este radicalismo la filosofía política de Richard Rorty.

3 El término profetismo lo acuña Ángel Rivero (1993: 49-64) para destacar que el neopragmatismo de Cornell West considera que los logros de la democracia estadounidense aún no han satisfecho el proyecto emancipador de la democracia. Creo que el neopragmatismo de Barber comparte esa dimensión profética.
} 
En tercer lugar, los elementos republicanos de la teoría de Barber no implican que ésta sea nostálgica. Nuestro autor alega que su teoría no es de «anticuario», sino que se adapta a las condiciones modernas, en especial al reconocimiento del conflicto social y al pluralismo (Barber, 1984: 117).

En cuarto lugar, la teoría política de Barber legitima la acción política con el fin de remover situaciones de injusticia, señalando los límites políticos y morales del abstencionismo liberal.

En quinto lugar, Barber plantea una teoría de la ciudadanía democrática que ofrece una alternativa tanto a la anomia provocada por la globalización de los mercados como a la reacción reivindicativa de comunidades pre-políticas de carácter adscriptivo y particularista (Barber, 1996; 2000). Su alegato a favor de la interdependencia en el mundo globalizado abre posibilidades a un nuevo modelo de relación entre las civilizaciones (Barber, 2003).

Por último, la teoría de la política de Barber, ante los discursos de pseudorenovación democrática de tinte populista, mantiene una concepción fuerte de la ciudadanía, que no confunde la participación cívica con la movilización, ni la transformación de los sistemas políticos liberales con la milagrería política (Barber, 1984; 1998).

En este contexto, me interesa desarrollar en este artículo la relación que Barber establece entre la necesidad de la acción política, la incertidumbre epistemológica del ámbito político y la deliberación. Las dos primeras forman parte de lo que Barber denomina condiciones de la política. Estas condiciones explican la inevitabilidad de la política y, entre ellas, la necesidad de la acción y la incertidumbre son muy representativas de nuestros tiempos globalizados. La deliberación, por su parte, es un elemento fundamental de la respuesta que la democracia fuerte ofrece a estas condiciones.

\section{Las condiciones de la política}

Según Barber, cualquier teoría de la política debe ofrecer una respuesta al reto que plantean las condiciones de la política. A su juicio, la democracia fuerte es el modelo de democracia que mejor responde a estas condiciones ${ }^{4}$. Precisamente, Barber enumera estas condiciones al

\footnotetext{
4 Puede argumentarse en contra que estas condiciones son sólo los presupuestos paradigmáticos de su teoría y no una realidad evidenciada. Por ejemplo, Cortina (1993: 105-106) critica la tesis de la inexistencia de presupuestos independientes previos al
} 
afirmar que «la esfera política está marcada por condiciones que imponen una necesidad de acción política, así como de opciones públicas razonables, en presencia del conflicto y en ausencia de presupuestos privados o independientes para el discernimiento» (Barber 1984: 120).

En primer lugar, Barber señala que la política es el ámbito de la acción, del hacer capaz de transformar el entorno y de afectar al espectro de posibilidades de otros hombres. Esta afirmación no es una obviedad, pues critica la tendencia del liberalismo a confundir la política con el ámbito del conocimiento - de la contemplación-, con el ámbito de las relaciones mecánicas - del movimiento no libre-, con el ámbito de las instituciones — de lo fijado-, con el ámbito de la acción de unos - los representantes- y de la inacción de otros - los representados- (Barber, 1984: 122). La orientación a la acción justifica toda la vida democrática, en especial, su dimensión deliberativa 5 .

En segundo lugar, la política es un ámbito de publicidad. La política es siempre acción, pero no toda acción es política porque no toda acción necesariamente es pública. La publicidad de una acción surge del sujeto que la realiza - una acción es siempre pública cuando la realiza la comunidad-, surge de la intención del sujeto de afectar en el ámbito público y, por último, la publicidad surge del resultado de la acción, o incluso del resultado agregado de muchas acciones que en su individualidad serían privadas (Barber, 1984: 123).

En tercer lugar, para Barber la política está determinada por la necesidad. En el ámbito político la inacción es una forma de acción, la nodecisión, una forma de decisión, y no nos eximen de la responsabilidad ante los resultados de los acontecimientos. Nuestro autor critica el abstencionismo de la teoría política liberal, que niega la legitimidad de los efectos producidos por la intervención política consciente y sin embargo legitima cualesquiera que fueren los resultados inconscientes de las fuerzas del mercado (Barber, 1984: 126).

En cuarto lugar, Barber sostiene que la política es el ámbito de la elección. La elección es política cuando es el resultado consciente de una deliberación previa. La elección impulsiva o arbitraria no puede considerarse elección política. La libertad de la opción política reside en la conciencia de la ciudadanía que la toma. La conciencia y la deliberación dis-

juicio político y, por tanto, la negativa de Barber a elaborar una fundamentación filosófica de su teoría.

5 Como pretendo demostrar, Barber es un precursor del actual debate de la democracia deliberativa. Muchos de los tópicos que señala han sido recogidos con posterioridad por los más eminentes proponentes de la deliberación. Así, la relación entre la deliberación democrática y la acción ha sido retomada por Amy Gutmann (2004: 276277), Jon Elster (2007: 123) o James Bohman (1996: 57). 
tinguen a la ciudadanía de la masa pues «hablar en el ámbito de la política de aquellos que deciden mediante la deliberación y actúan con responsabilidad, es hablar de los ciudadanos [...] Las 'masas' según este criterio no podrían contarse, ni siquiera cuando 'votan'» (Barber 1984: 126).

En quinto lugar, la política es el ámbito de la razonabilidad. La razonabilidad es una respuesta a la ausencia de certidumbre epistemológica, un punto intermedio entre la arbitrariedad y la racionalidad científica. La razonabilidad implica algo más que la negociación entre intereses, exige la presencia de empatía para reformular en términos públicos los intereses privados, para ponerlos en un contexto social que incluye los intereses de los otros, «ser razonable, por tanto, no significa negar el Yo, sino colocarlo en el contexto del Otros» (Barber, 1984: 128) ${ }^{6}$.

En sexto lugar, Barber sostiene que la política es el ámbito del conflicto. La teoría liberal pretende resolver el conflicto aludiendo a un consenso preexistente, racionalmente deducible o empíricamente constatable; mientras que para Barber, la inexistencia de este consenso es una de las razones que dan sentido a la política porque «si uno afirma que la condición de la unanimidad y del consenso que la política desea alcanzar a través de sus artes existe ya por naturaleza, entonces la política pierde su propósito y pasa a ser superflua» (Barber, 1984: 128). Aunque Barber no abunda en las causas del conflicto, tal y como sí hacen Amy Gutmann y Dennis Thompson — quienes sostienen que el conflicto se produce por las condiciones de escasez, por la generosidad limitada de los sujetos, por la incompatibilidad inherente entre algunos valores y por la comprensión incompleta de los problemas en cuestión-, concuerdan en que la deliberación ofrece una respuesta para superar de forma legítima, aunque provisional, este conflicto (Gutmann \& Thompson, 1996: 41-43). Esta forma de reconocer y abordar el conflicto manifiesta la reconocida influencia rousseauniana de Barber?

En séptimo lugar, por último, la política sufre la ausencia de presupuestos independientes, pues «donde hay un conocimiento cierto, una ciencia verdadera o una verdad absoluta, no existe conflicto que no pueda ser resuelto apelando a la unidad de la verdad $-\mathrm{y}$, por tanto, la política

\footnotetext{
6 Es apreciable la confluencia entre la razonabilidad formulada por Barber, la reciprocidad sostenida por Gutmann \& Thompson (1996: 1) y la genuidad descrita por Nino (2003: 171-172).

7 Una muestra de esta deuda es la relación entre el conflicto político y el proceso democrático. Javier Peña (1995: 131) afirma que Rousseau «tiene una clara intuición de la naturaleza conflictiva de la sociedad moderna» por lo que es necesario un contrato que funde una comunidad deliberante de iguales, pues «una sociedad constituida sobre el pacto social liberal no suprime el antagonismo del estado de guerra, sólo lo enmascara». Esta afirmación también vale para describir la postura de Barber.
} 
no es necesaria [...] donde se detiene el consenso empieza la política» (Barber, 1998: 129). No podemos aspirar a nada más que a la razonabilidad para legitimar la acción política, pues si hubiera certeza esa acción ya no sería política sino técnico-científica (Barber, 1984: 130-131).

\section{Las condiciones de la política y la democracia fuerte}

La democracia fuerte responde a la política como ámbito de la acción porque fomenta la participación y «crea un público con capacidad para la deliberación y la adopción de decisiones públicas razonables» (Barber, 1984: 133). La creación de la ciudadanía es el producto de la política entendida en su modo participativo, la identidad comunitaria no es un antecedente de la política, como sostienen las concepciones organicistas y naturalistas. El proceso democrático participativo permite el autogobierno porque vertebra una ciudadanía.

Barber (1998) señala que la teoría liberal reduce la capacidad de elección al consentimiento que subyace en la relación representativa. Sin embargo, en la democracia fuerte la elección surge de un compromiso cívico con la deliberación que empodera a los ciudadanos y permite superar las formas de elección mercantiles y clientelares (Barber, 1984: 134).

La razonabilidad es «una actitud que genera la misma política de la democracia fuerte» (Barber, 1984: 135). Esto supone reconocer la dimensión educativa, transformadora del sujeto, de la dinámica deliberativa, algo que evidentemente molesta a los autores que conciben el proceso democrático de forma «mecánica», como por ejemplo es el caso de Laporta (2001: 22-28).

La democracia fuerte no aspira a la completa resolución del conflicto, sino a resoluciones provisionales e históricamente contextualizadas en un proceso permanente de deliberación; por ello se aproxima más al pluralismo político liberal que a las teorías comunitaristas que aspiran al consenso ${ }^{8}$.

Por último, la democracia fuerte responde a la ausencia de presupuestos independientes desde una teoría política desvinculada de concepciones pre-políticas de carácter metafísico. Sin embargo, esto no supone que sea a-valorativa, ni relativista, ni nihilista. La autonomía de la política en la teoría de la democracia fuerte está más bien en relación con

8 Este es otro rasgo de la propuesta de Barber heredado por el debate posterior. La negación de la posibilidad de un consenso definitivo será retomada por Shapiro (2004: 194) como rasgo inherente de la democracia deliberativa. 
el papel que los valores y las distintas pretensiones de la verdad tienen en el proceso político. Es decir, dado el pluralismo, no es posible fundamentar la política en ninguna concepción pre-política, pero todas ellas contribuyen a la configuración de los valores públicos porque todas interactúan en la deliberación.

La teoría de la democracia fuerte relaciona la legitimidad política con la deliberación. En el proceso deliberativo los valores entran en el juego de su mutua transformación a través de la confrontación. De esta forma, el valor legitimado públicamente es un valor distinto al que sostenía una parte de la ciudadanía de forma privada. El proceso no consiste, pues, en una elección entre valores, sino en su recreación pública. Una democracia fuerte es capaz de defender valores con convicción, pues «hace que las opiniones y preferencias ganen legitimidad forzándolas a aceptar el reto de la deliberación y del juicio públicos» (Barber, 1984: 136) ${ }^{9}$.

Barber distingue la deliberación del regateo o la negociación. Al regatear, la elección pública se da entre opciones fijadas, el consentimiento legitima uno de los valores del ámbito privado tal y como estaba configurado antes de su elección. La teoría de la democracia fuerte pretende que el discernimiento público permita a los ciudadanos ver sus preferencias privadas de forma pública, posibilitando su transformación, «si un valor emerge del proceso político completamente inalterado por dicho proceso, entonces o sigue siendo un valor privado enmascarado en una norma pública o ya ostentaba un consenso previo que ha sido revelado en el proceso político» (Barber, 1984: 136).

La propuesta de Barber puede ser comparada con el «consenso por superposición»(Overlapping Consensus) de John Rawls. En ambos casos surge la idea de un acuerdo, pero en Rawls parece que este se produce por la superposición de doctrinas comprehensivas razonables y fijadas, mientras que en Barber se produce por la transformación en el debate de los valores de las doctrinas que concurren en él.

En el caso de Rawls, el problema político se refiere a la posibilidad de «una sociedad estable y justa, cuyos ciudadanos, libres e iguales, estén profundamente divididos por doctrinas religiosas, filosóficas y morales y aun inconmensurables» (Rawls, 1996: 165). La idea de consenso por superposición pretende encontrar el ámbito de convivencia común que permita «establecer y preservar la unidad y la estabilidad dado el pluralismo que la caracteriza» (Rawls, 1996: 165). De esta manera, la superposición implica que «las doctrinas razonables aceptan la concepción política, cada una desde su punto de vista» (Rawls, 1996: 165, la cursiva es mía).

Esta relación entre el grado de legitimidad política y el grado de deliberación será posteriormente remarcada por James Bohman (1996: 3). 
Desde la posición de Barber, el consenso por superposición no supera la privacidad, pues deja inalterado el valor de cada una de las doctrinas, aun en la esperanza de su confluencia. La idea del «consenso por superposición» no ayuda a resolver el conflicto, precisamente porque se basa en la existencia de un consenso previo -el ámbito de la superposición- que el proceso político sólo ayuda a desvelar. Esta idea se refuerza con el requisito de la razonabilidad de las doctrinas, es decir, el ámbito de conflicto entre los razonables es ciertamente limitado, precisamente por su razonabilidad. La deliberación transformadora de los valores que propone Barber permitiría la posibilidad de ampliar el ámbito de consenso previo, es decir, la posibilidad de que surja consenso donde antes había disenso ${ }^{10}$.

\section{Incertidumbre y deliberación}

En The Conquest of Politics, Barber (1988: 3) sostiene que «los límites sobre los que definimos y entendemos la filosofía no son necesariamente comparables con los límites sobre los que definimos y entendemos la política». En este sentido, critica a muchos filósofos liberales por no aceptar la incertidumbre del ámbito político y por reducirlo a las características del ámbito epistemológico. Critica la pretensión de alcanzar racionalidad en la política, es decir, certeza, en lugar de razonabilidad, la única forma de superar la arbitrariedad y el relativismo cuando la certeza no es posible ${ }^{11}$.

La filosofía y la política se distinguen como el pensamiento y la acción. El pensamiento y la acción pueden confluir, y de hecho no cabe duda de que nuestro autor considera que deben hacerlo (Barber, 1971: 37), pero no por ello deben confundirse. La confusión de la filosofía y de la política es problemática porque «deseando adaptarse a los criterios cognitivos más elevados, un filósofo así puede encontrarse reduciendo los problemas de la práctica política» (Barber, 1988: 4).

Indudablemente, pensamiento y acción, filosofía y política, confluyen, pues la función de la filosofía política según Barber (1988: 4) es «la

10 En este sentido, tal vez la propuesta más esperanzada la da Dryzek (2005: 218242), quien sostiene el potencial de la deliberación para resolver incluso los conflictos generados por identidades construidas de forma antagónica.

11 No cabe duda de que esta posición tiene sus limitaciones en el ámbito de la argumentación filosófica, pero puede resultar útil en el ámbito político. Como afirma Gil Soldevilla (2004: 146) acerca de la filosofía de Walzer, no se trata de salir de la caverna y lograr ideales universales, sino de desplegar el potencial de los valores compartidos entre nuestras tradiciones, es decir, internarnos en ellos. 
creación de una praxis genuina en la que teoría y práctica sean reconciliadas». Sin embargo, Barber considera que la filosofía liberal ha producido un modelo de discurso filosófico-político metateórico que impide abordar eficazmente los problemas políticos relevantes, «el resultado es una distorsión de nuestro sentido de lo político que ha menoscabado nuestra política al menos un poco y nuestra comprensión filosófica de la política bastante más» (Barber, 1988: 5).

La filosofía política liberal, a juicio de Barber (1988: 6), «desea establecer unos fundamentos epistemológicos irrebatibles para el conocimiento moral y político» que permitan superar el relativismo y la arbitrariedad. Esta actitud la denomina fundamentalismo. Por su parte, Barber también pretende superar el relativismo y la arbitrariedad, pero reconociendo la incertidumbre. Por este motivo debemos conformarnos con la razonabilidad, una meta política suficientemente elevada si tenemos en cuenta la realidad de nuestras neodemocracias (Barber, 1984: xiii).

La búsqueda de la certeza en el ámbito político es disfuncional porque impide el desarrollo práctico de la deliberación y de la participación. Por ello, la primera víctima de la negación de la incertidumbre política es la democracia misma, «el primer objetivo político del fundamentalismo es de hecho la misma democracia, el concepto de que un público tiene la responsabilidad de legislar no sólo su propio destino en común, sino también los criterios por los cuales lo que es común y lo que es individual (lo que es público y lo que es privado) son determinados» (Barber, 1988: 7).

La negación de la incertidumbre convierte a los filósofos de la política en una nueva clerecía que administra el discurso político, lo expresa en términos ininteligibles para los ciudadanos y los desmotiva. Con la desmotivación de los ciudadanos la incompetencia cívica está servida. Barber sostiene en este punto que los términos políticos deben ser construidos, transformados y manejados por los ciudadanos que tienen el deber y el derecho del resolver los conflictos políticos ${ }^{12}$.

A mi entender, las condiciones de la política que Barber ha descrito tienen su piedra clave en la relación entre la incertidumbre y necesidad de la acción. La deliberación pública funciona como un mecanismo de mediación entre estos dos polos, produciendo una razonabilidad pública y

12 Esta posición se contrapone a cierto elitismo que hay en otras teorías de corte republicano. En efecto, un filósofo como Pettit (1999: 19-25), por ejemplo, no sólo rechaza las interpretaciones participacionistas del republicanismo, «populistas» en sus palabras, sino que sostiene que la función del filósofo es examinar y ampliar el lenguaje de la discusión política. 
transformando al sujeto de forma que sea capaz de comprender esa razonabilidad, determinar bienes públicos y actuar para realizarlos.

En este contexto, el problema de la incertidumbre está en el centro de la discusión doctrinal sobre la democracia deliberativa que ha sucedido a la teoría de la democracia fuerte propuesta por Barber. David Miller, por ejemplo, diferencia entre la democracia deliberativa y la epistémica, pues la segunda presume que existe una decisión correcta objetiva y que es más probable que esta opción correcta se alcance a través de un proceso democrático. Así, el mismo autor describe el teorema de Condorcet, que relaciona el problema del descubrimiento de la verdad y la deliberación con la idea de probabilidad. Al final, para Miller lo que define la democracia epistémica es la búsqueda de la verdad en un sentido comparable al que Barber da a este término, en relación con la certeza y otros criterios de exigencia epistemológica (Miller, 2003: 182-184) ${ }^{13}$.

Es relevante para comprender la genealogía de la teoría barberiana que Miller sostiene que, a pesar de otras opiniones, la teoría de la democracia de Rousseau y su concepción de la deliberación no es epistémica. Por el contrario, Miller define la democracia deliberativa como aquella que no pretende llegar a la verdad, «a ningún criterio trascendente de justicia o corrección» (Miller, 2003: 185), sino a un acuerdo razonable. Al igual que Barber, Miller (2003: 184) sostiene que la «concepción epistémica impone un criterio elevado para la toma de decisiones políticas irrealista», y ofrece una respuesta análoga a la de Barber, es decir, aunque la razonabilidad no resuelve la incertidumbre, ayuda a sobrellevarla.

Según Shapiro (2003: 124), la idea de una solución correcta como elemento definitorio de la deliberación democrática no incluye que ésta tenga un nivel epistemológico superior a las otras posibles soluciones. Para este autor la corrección está más en relación con la pretensión de los participantes a la hora de intervenir en el proceso deliberativo, ya que estos se comprometen en la deliberación porque creen que pueden acercarse a algo como la verdad, es decir, este concepto actúa como ideal regulativo.

Por último, es reseñable la posición de Amy Gutmann y Dennis Thompson en Democracy and Disagreement, una defensa de la democracia deliberativa que toma como presupuesto el inevitable desacuerdo moral que impregna las relaciones políticas. Gutmann y Thompson parten de una posición muy próxima a la de Barber: el conflicto moral es relevante en el ámbito político porque «en política la necesidad es encontrar algu-

13 Otros filósofos como Pettit (2003: 138-158), List \& Goodin (2001: 277-306), o Nino (2003: 178), también estudian la relación entre la deliberación y la posibilidad de alcanzar la verdad. 
nas bases sobre las que justificar las decisiones colectivas aquí y ahora en ausencia de un conocimiento que las fundamente» (Gutmann \& Thompson, 1996: 4-5). La postura de estos autores excluye la pretensión de asegurar el fundamento de los principios morales que intervienen en la política de forma filosófica pues aunque «la deliberación actual es inevitablemente defectuosa, también lo es la reflexión filosófica practicada en la política» (Gutmann \& Thompson, 1996: 3).

El pragmatismo de Barber al afirmar la incertidumbre del ámbito político no puede confundirse con el discurso líquido criticado por Bauman (2006). El discurso de Barber no es un discurso postmoderno, de derrota o de cansancio, de escepticismo o de cinismo. Por el contrario, la insistencia en la incertidumbre es compatible con la lucha, compartida con el liberalismo, contra el relativismo y la arbitrariedad en la política. La propuesta de Barber permite aunar el reconocimiento del abismo sobre el que navegamos y al tiempo reivindicar la necesidad de convicciones democráticas para afrontar los retos a la libertad, a la igualdad y a la fraternidad.

\section{Deliberación y sociabilidad}

La pretensión de explicar el discernimiento político desde categorías meramente individuales y cognitivas nos aleja, según Barber, de lo que realmente sucede cuando los ciudadanos se plantean una cuestión política. Si el discernimiento político destaca por la incertidumbre y la comunalidad, nuestro autor sostiene que «el viaje desde la opinión privada al discernimiento político no sigue el camino desde el prejuicio al verdadero conocimiento, sino que sigue el de la soledad a la sociabilidad» (Barber, 1988: 199) ${ }^{14}$.

La sociabilidad aparece como la clave del juicio político, definido como una actividad pública de los ciudadanos en común. Sólo habrá discernimiento político cuando los ciudadanos actúen como tales en un contexto de interacción que les permita actuar de forma colegiada. De estas características se deduce que para Barber (1988: 200) «la democracia resulta ser el único soporte del discernimiento político, porque maximiza la interacción y garantiza la diversidad y la generalidad que es crucial en un discernimiento prudente». Esta relación entre deliberación y sociabilidad será destacada también por James Bohman, para quien la delibera-

14 Esta relación entre deliberación y contexto social será heredada por otros proponentes de la democracia deliberativa (Ackerman \& Fishkin, 2003: 7-9; Goodin, 2003: 54-79). 
ción pública es «un proceso dialógico de intercambio de razones con el propósito de resolver situaciones problemáticas que no pueden ser resueltas sin cooperación y coordinación interpersonal», de forma que «la deliberación no es tanto una forma de discurso o argumentación como una actividad conjunta y cooperativa» (Bohman, 1996: 27) ${ }^{15}$.

El discernimiento político no puede ubicarse en el eje «opinión»«verdad», que suele mediarse con el concepto de «intersubjetividad». Estas categorías se encuentran, según Barber, en una perspectiva epistemológica, mientras que el discernimiento político está más allá de ellas porque se mueve en otro eje. Lo intersubjetivo busca explicar la coincidencia de los juicios individuales, sin embargo, el discernimiento político no surge de una conciencia individual, sino que surge de la interrelación entre los sujetos, por lo que «el discernimiento político es en este sentido un discernimiento en común en su forma más alta» (Barber, 1988: 203).

La diferencia entre estas dos dimensiones es relevante en lo que se refiere a la transformación del sujeto a través de la deliberación. Según Barber, la intersubjetividad no incluye la transformación del sujeto, sino el mero acuerdo de conciencias individuales. Así, nuestro autor afirma que «donde la intersubjetividad sugiere el acuerdo entre individuos, la ciudadanía sugiere la transformación de los individuos por su pertenencia a una asociación política de sujetos que ven en común y que producen un discernimiento en común» (Barber, 1988: 203).

\section{La rehabilitación de la política: incertidumbre, deliberación y acción política}

A nuestro entender, la obra de Barber supone una rehabilitación de la política tanto por su recuperación de la deliberación como de la legitimidad de la acción política. En este contexto, al analizar las tendencias internas del liberalismo, Barber pone en relación su dimensión apolítica (cuando no anti-política) con la deslegitimación de la acción política.

El abstencionismo liberal esconde una sospecha hacia la democracia, a la que se le han imputado las patologías de los sistemas democráticoliberales por un exceso de participación. Nuestro autor afirma -en línea con la crítica de Pateman (1970: 1-3)- que para el liberalismo «el go-

15 En esta línea, Shapiro (2003: 122) sencillamente contrapone el concepto de «reflexión» al concepto de «deliberación», que implica siempre interacción y cooperación. Por su parte, Manin (1987) y Fearon (1998) también establecen la inherente relación entre deliberación y sociabilidad. 
bierno popular porta dentro de sí la semilla del totalitarismo» (Barber, 1984: 94).

Por este motivo, Barber analiza las tres tendencias internas $-\mathrm{y}$ contradictorias- que laten en el seno de la teoría política liberal: la tendencia anarquista, la tendencia realista y la tendencia minimalista. La primera y la última son muy refractarias a la posibilidad de legitimar la acción política.

La primera tendencia, la anarquista, concibe la libertad como la sublimación de la independencia y exalta el individualismo (Barber, 1984: 99). Esta tendencia tiende a reducir a cero la capacidad de la ciudadanía para definir bienes públicos y para realizarlos a través de la acción política. Barber reconoce la eficacia histórica de esta tendencia para enfrentarse a las diferentes formas de despotismo que limitan la libertad externa, formas de despotismo antiguas, que toman la forma de jerarquía, de estatus, o de un poder absoluto. Sin embargo, para nuestro autor, esta concepción no es suficiente como para enfrentarse a las formas de despotismo sutil actuales que no imponen una restricción externa sino una dominación moral (Barber, 1984: 99).

Los problemas generados por la apolitización de la tendencia anarquista, precisamente, intentan ser superados por la tendencia realista. Esta tendencia explica las manifestaciones de poder en los sistemas liberales y es la razón de que hayan desplegado en muchos momentos dinámicas imperiales.

$\mathrm{Al}$ respecto, Barber afirma que el liberalismo sostiene una comprensión físico-mecanicista de la libertad definida como ausencia de restricciones, por tanto, como ausencia de poder político. A su juicio, la tendencia anarquista sostiene que el fin último de la política es preservar la libertad, cuya mayor amenaza es el poder, pero paradójicamente la política está indisolublemente ligada al poder, como reconoce la tendencia realista. Así, la aporía que desgarra al liberalismo es cómo hacer compatibles estos dos elementos inevitablemente unidos. De una u otra forma, la teoría liberal debe responder a este dilema: «¿Cómo podemos preservar la libertad sin caer en el anarquismo?, ¿Cómo podemos usar el poder sin caer en la tiranía?» (Barber, 1984: 103). Desde una comprensión antagónica de la libertad y el poder el liberalismo busca un equilibrio imposible, pues «la libertad, al negar la tiranía, engendra anarquía; el poder, al frustrar la anarquía engendra tiranía» (Barber, 1984: 103). En este contexto, nuestro autor ofrece una concepción alternativa de la libertad y del poder que permite su reconciliación (Barber, 1971).

Finalmente, la tendencia minimalista del liberalismo intenta realizar una mediación que permita superar la aporía. Si para garantizar la libertad es necesaria la existencia de poder, que al tiempo es su máxima amenaza, la solución consiste en minimizar el poder al necesario para garantizar la 
libertad. La actitud que toma la tendencia minimalista para minimizar el poder es el escepticismo. Si en el ámbito de la ciencia no es posible afirmar verdades con certeza, afirma el escéptico liberal, mucho menos lo es en el ámbito de la política, por lo que se corre grave riesgo de limitar de forma ilegítima la libertad al pretender determinar fines públicos. Aunque Barber aprecia algunas bondades de la actitud escéptica dentro de los márgenes del sistema democrático liberal, critica su debilidad, pues «no es una defensa particularmente útil contra el fanatismo, y los escépticos tolerantes que piensan que nada puede saberse son aliados inefectivos de la civilización cuando los fanáticos que piensan que lo conocen todo se han puesto en marcha» (Barber, 1984: 105).

Desde la perspectiva de nuestro autor, la proyección de la epistemología escéptica en el ámbito político tiene dos errores. El primero, pensar que la política debe adaptarse a las exigencias de certeza de la epistemología. El segundo error es generar una práctica política pusilánime, pues la duda no es buena defensora de la democracia o, en palabras de Barber (1984: 105), «la lucha por la libertad precisa de una fe enérgica».

El escepticismo del minimalismo condena a la ciudadanía a la pasividad, pero Barber (1984: 106) sostiene que «en un mundo donde las acciones son necesarias y las consecuencias inevitables, la inseguridad del liberal no significa que nada pase, sólo que él no causa que algo pase». De esta manera, Barber estima que el minimalismo liberal se asegura de no imponer ningún bien público, pero de ello resulta la imposición de los intereses privados, lo que a la postre resulta aún más dañino para la libertad.

La teoría de Barber comparte, mucho más de lo que pudiera parecer a simple vista, con el escepticismo epistemológico del minimalismo liberal, pues también define el ámbito político como una esfera de incertidumbre, en el que el juicio público y las decisiones políticas no se fundamentan en unos principios absolutos e independientes que puedan ser tomados como verdad. Sin embargo, la respuesta que ofrece Barber es distinta a la del minimalismo. Frente a la incertidumbre del ámbito político, Barber (1984: 108) sostiene que la respuesta adecuada no es la pasividad pública, sino la actividad, pues «sólo una política activa y una ciudadanía democrática pueden evitar la transformación del relativismo en nihilismo o del escepticismo filosófico en impotencia política», y no cabe duda de que el nihilismo y la impotencia política son dos de las lacras de nuestro mundo globalizado. 


\section{REFERENCIAS}

-Ackerman, B. \& Fishkin, J. (2003). Deliberation Day (págs. 7-30). En J. Fishkin y P. Laslett (eds.), Debating Deliberative Democracy. Malden, M.A.: Blackwell Publishing Ltd.

-Barber, B. R. (1971). Superman and Common Men: Freedom, Anarchy and the Revolution. New York: Praeger Publishers.

-Barber, B. R. (1974). The Death of Communal Liberty: A History of Freedom in a Swiss Mountain Canton. Princeton: Princeton University Press.

-Barber, B. R. (1975). Liberating Feminism. New York: Continuum Books/ Seabury Press.

-Barber, B. R. (1981). Marriage Voices: A Novel. New York: Summit Books.

-Barber, B. R. (1984). Strong Democracy: Participatory Politics for a New Age. Berkeley: University of California Press (hay trad. cast. en (2004), Córdoba: Almuzara).

-Barber, B. R. (1988). The Conquest of Politics: Liberal Philosophy in Democratic Times. Princeton: Princeton University Press.

-Barber, B. R. (1994). An Aristocracy of Everyone: The Politics of Education and the Future of America. New York: Oxford University Press.

-Barber, B. R. (1996). Jihad versus McWorld. New York: Ballantine Books.

-Barber, B. R. (1998). A Passion for Democracy: American Essays. Princeton: Princeton University Press (hay trad. Cast. que no contiene todos los artículos de la compilación original editada por Princeton University Press, en (2006), Córdoba: Almuzara).

-Barber, B. R. (2000). Un Lugar Para Todos. Barcelona: Paidós.

-Barber, B. R. (2001). The Truth of Power: Intellectual Affairs in the Clinton White House. New York: W. W. Norton.

-Barber, B. R. (2003). Fear's Empire: War, Terrorism and Democracy in an Age of Interdependence. New York: W.W. Norton.

-Barber, B. R. (2008). Consumed: How Markets Corrupt Children, Infantilize Adults, And Swallow Citizens Whole. New York: W.W. Norton.

-Barber, B., Friedrich, C. J., \& Curtis, M. (1969). Totalitarianism in Perspective. New York: Praeger Publishers.

-Bauman, Z. (2006). Vida Liquida. Barcelona: Paidós.

-Bohman, J. (1996). Public Deliberation. Pluralism, Complexity, and Democracy. Cambridge: Cambridge MIT Press.

-Cortina, A. (1991). La moral del camaleón. Madrid: Espasa-Calpe.

-Cortina, A. (1993a). Ética Aplicada y Democracia Radical. Madrid: Tecnos.

-Cortina, A. (1993b). Democracia, el dogma de nuestro tiempo. Claves de Razón Práctica (29), 25-33.

-Del Castillo, R. (1996). De R. Rorty a J. Dewey: notas sobre filosofía, democracia y comunidad. Isegoría (14), 173-184.

-Dryzek, J. S. (2005). Deliberative Democracy in Divided Societies: Alternatives to Agonism and Analgesia. Political Theory, 33 (2), 218-242. 
-Elster, J. (2007). El mercado y el foro: tres formas de teoría política. Cuaderno Gris (9), 103-126.

-Fearon, J. D. (1998). Deliberation as Discussion. En J. Elster (Ed.), Deliberative Democracy (págs. 44-68). Cambridge: Cambridge University Press.

-Gil Soldevilla, J. (2004). Una reflexión en torno al concepto de libertad como no-dominación en Walzer y Pettit. Enfoques, XVI (2), 141-150.

-Goodin, R. E. (2003). Democratic Deliberation Within. En J. Fishkin y P. Laslett (Eds.), Debating Deliberative Democracy (págs. 54-79). Malden, M.A.: Blackwell Publishing.

-Gutmann, A. (2004). Democracia deliberativa y regla de la mayoría: una réplica a Waldron (págs. 269-278). En H. Hogju Koh y R. C. Slye (Comps.), Democracia deliberativa y derechos humanos. Barcelona: Gedisa.

-Gutmann, A. \& Thompson, D. (1996). Democracy and Disagreement. Cambridge, M.A.: Harvard University Press.

-Herrera, A. (2005). Democracia deliberativa y desarrollo biotecnológico. Revista iberoamericana de ciencia tecnología y sociedad, 2 (6), 211-221.

-Laporta, F. (2001). Los problemas de la democracia deliberativa. Claves de Razón Práctica (109), 22-28.

-List, C. \& Gooding, R. E. (2001). Epistemic Democracy: Generalizing the Condorcet Jury Theorem. The Journal of Political Philosophy, 9 (3), 277-306.

-Manin, B. (1987). On Legitimacy and Political Deliberation. Political Theory, 15 (3), 338-368.

-Miller, D. (2003). Deliberative Democracy and Social Choice. En J. Fishkin \& P. Laslett (Eds.), Debating Deliberative Democracy (págs. 182-199). Malden, M.A.: Blackwell Publishing Ltd.

-Nino, C. (2003). La constitución de la democracia deliberativa. Barcelona: Gedisa.

-Pateman, C. (1970). Participation and Democratic Theory. Cambridge: Cambridge University Press.

-Peña, J. (1995). Rousseau y la idea de comunidad política. Isegoría (11), 126-143.

-Pettit, P. (1999). Republicanismo. Una teoría sobre la libertad y el gobierno. Barcelona: Paidós.

-Pettit, P. (2003). Deliberative Democracy, the Discursive Dilemma, and the Republican Theory. En J. Fishkin y P. Laslett (Eds.), Debating Deliberative Democracy (págs. 138-162). Malden, M.A.: Blackwell Publishing Ltd.

-Rawls, J. (1996). Liberalismo político. Barcelona: Crítica.

-Rivero, A. (1993). Liberalismo, democracia y pragmatismo. La teoría política de Cornel West. Isegoría (8), 49-64.

-Shapiro, I. (2003). Optimal Deliberation? En J. Fishkin y P. Laslett (Eds.), Debating Deliberative Democracy. Malden, M.A.: Blackwell Publishing Ltd.

-Shapiro, I. (2004). Aspiraciones grupales y política democrática (págs. 173188). En H. Hogju Koh y R. C. Slye (Comps.), Democracia deliberativa y derechos humanos. Barcelona: Gedisa. 
Sumario: 1. Las condiciones de la política; 2. Las condiciones de la política y la democracia fuerte; 3. Incertidumbre y deliberación; 4. Deliberación y sociabilidad; 5. La rehabilitación de la política: incertidumbre, deliberación y acción política; Referencias. 